rotation. Many trainees will not wish to move house at the mid-point of the scheme but may commute to their posts by train. If their posts require the use of a car, the provision of 'Crown' or lease cars should be considered.

\section{Ideally, the administration of a scheme should be done by a senior clinician whose time is funded}

There is no doubt that administering a large regional scheme makes significant in-roads into the time of the scheme organiser. We estimate that the organisation of our scheme will take approximately four sessions per week of consultant time and have suggested that funding should be made available for this. We believe that in a large regionally based scheme decisions should not be taken by a large committee remote from the trainees in the absence of an organiser actually having some detailed knowledge of each trainee in the region. However, in keeping with the general non-funding of postgraduate training in hospital specialties, no funds have as yet been identified for this particular function although a consultant organiser's travel expenses will be reimbursed by the region. There will need to be regular meetings between participating district consultants in the regional scheme and the scheme organiser in order to sort out any problems arising from the implementation of this scheme and in addition, meetings with trainees to ensure that their educational needs are being met. This should not supplant the work carried out by individual district clinical tutors.

Finally, there is no doubt that administering such a scheme will also require a consumables budget, e.g. paper, photocopying, telephone calls, etc., and allowance must be made for these expenses, as well as for secretarial/administration time. Perhaps the new arrangements planned by the Department of Health will provide adequate funding for these activities for the first time.

\section{Acknowledgements}

We are grateful to Drs N. Farhoumand, J. Hargreaves, W. Mikhail, K. Sivakumar, and S. Wood, scheme organisers in SE Thames for their invaluable assistance in formulating the scheme outline. Dr W. Bamber previously served on the scheme committee. Our thanks are extended to $\mathrm{Dr} \mathbf{R}$. Symonds, The College Regional Adviser, Dr R. King, the emeritus Regional Postgraduate Dean and Mr J. Lee, the Regional Medical Staffing officer.

\section{References}

Council of the Royal College of Psychintrists (1990)

Statement on psychiatric practice and training in British multi-ethnic society. Psychiatric Bulletin, 14, 432-437.

DEPARTMRNT OF HEALTH (1988) Achieving a Balance. London: HMSO.

\title{
Psychiatric knowledge and attitudes in Nottingham medical students
}

\author{
J. PAul Ryley, Lecturer in Psychiatry, A Floor, South Block, University Hospital, \\ Nottingham NG7 2UH; and Trevor FrIEDMaN, Consultant Liaison Psychiatrist, \\ Leicester General Hospital, Gwendolen Road, Leicester
}

Psychological and psychiatric issues represent a significant proportion of the workload of all doctors. Nonetheless junior doctors often have an unsatisfactory knowledge of psychiatry. Previous studies have examined how hospital doctors say they manage psychological problems (Mayou \& Smith, 1986), and attitudinal factors among medical students (Wilkinson et al, 1983).
In Nottingham, medical students undertake an integrated course with a strong emphasis on the behavioural sciences, and on the psychological aspects of medicine, surgery, obstetrics and child health. It was therefore hypothesised that Nottingham students would be familiar with some basic psychological and psychiatric issues before they began their psychiatric clerkship. Similarly, the 
volume of specific knowledge that needs to be learnt during the psychiatry attachment may lead to skills relevant to a nonpsychiatrist being overlooked. It was hypothesised that our students' previous experience would enable them to assimilate these more general applications of psychiatry to a good standard and retain them until after qualification.

\section{The study}

Students completed a questionnaire at the beginning of their eight week attachment; at the end of their formal teaching in week seven (i.e. one week before their end-of-attachment examination); and during their first month as house officers. They were not informed at each completion that there would be further questionnaires.

The questionnaire was designed to cover areas of psychiatry relevant to doctors practising in a general medical or general practical setting. It included items about the detection and assessment of depression, alcoholism and deliberate self harm; the prevalence rates of common psychiatric conditions; common misconceptions about psychiatric illness; and attitudes towards the attachment and towards ECT.

\section{Findings}

Of the students, 244 ( $50.8 \%$ male) in 11 consecutive clerkships completed the questionnaires at the beginning and end of the clerkship, but missing data reduced the number of complete pairs of forms to $191(78 \%$ of total). One hundred and twenty-three students, comprising one complete year, were circulated with the questionnaire during their first month as a house officer but due to the low response rate $(\mathrm{N}=31,25 \%)$ results were not analysed.

The mean score at the beginning of the attachment was 12.8 (s.d. \pm 2.8 ) increasing significantly by the end to 17.3 (s.d. \pm 2.3$)(P<0.0001)$. Maximum possible score was 22 .

\section{Individual items}

Only $43 \%$ initially scored two or three when asked to list three features of suicidal intent, in spite of their experience of relevant teaching before the attachment on medical firms: by the second questionnaire this had risen to $86 \%$. Five per cent initially suggested that a history of alcohol abuse should be sought after an overdose, rising to $35 \%$ by the end.

Initially students' assessment of the alcoholic patient included $66 \%$ listing three or four ways (out of four requested) that alcoholics may present to a GP; and $55 \%$ knowing to ask the patient how much he drinks. These rates improved over the attachment, but at the second assessment still only $70 \%$ would ask the patient how much he drank when assessing the extent of his abuse.
Initially $44 \%$ scored three or four out of four on recognising hidden depression, and $32 \%$ knew the name of a 'firstline' tricyclic antidepressant. These figures rose to $60 \%$ and $96 \%$ at the end. However, of those who knew a antidepressant at the second assessment, only $60 \%$ quoted a dose in the range $125-200 \mathrm{mg} /$ day for full dosage.

Of the five questions on common misconceptions, four were answered correctly by over $70 \%$ of students. They answered less well on the question 'mental illness is commoner among the mentally handicapped', correct answers rising from $24 \%$ to $69 \%$ over the attachment $(P<0.0001)$.

Students were surprisingly accurate about the lifetime prevalence of common psychiatric conditions before they started their attachment and this accuracy improved in six out of seven of the conditions enquired about. However, concerning suicide ('correct answer' 1\%), there was underestimating which persisted to the end of the attachment. The mode was $0.2 \%$ and median $0.5 \%$ before and after, though at the end of the attachment there was some shift towards the higher rate; $16 \%$ and $25 \%$ respectively estimated correctly (a significant improvement, $P<0.02$ ).

Initially $58 \%$ would have ECT themselves if severely depressed. The rate increased to $95 \%$ at the end of the attachment $(P<0.0001)$.

At the beginning $16 \%$ thought the psychiatry attachment was not long enough and this rose to $34 \%$ at the end of the attachment $(P<0.0001)$.

\section{Associations with responses}

Very few sex differences were evident. In particular there were no differences in overall scores, career choice, or attitude to ECT.

Examination results correlated with initial questionnaire score (Spearman's $\rho=0.18, P<0.005$ ) and final questionnaire score (Spearman's $\rho=0.31$, $P<0.001$ ) but not with improvement over the attachment. Grades for personal effectiveness (a measure of how hard they try and how good they are with patients) also did not correlate with improvement.

The four students who failed the attachment showed only slightly lower questionnaire scores than the group as a whole (mean scores of 11.5 initially, 14.3 at the end: sample means 12.8 and 17.3).

\section{Career choice}

Nine students $(4.1 \%)$ indicated an intention to choose psychiatry at the start of the attachment (three in combination with another area of medicine) and $21(9.8 \%)$ afterwards (nine in combination). This increase was significant $(P<0.0005)$. The intention to become a psychiatrist was found in more high scorers initially $(P<0.0001)$ but this relationship was lost by the end of the attachment. 


\section{Comment}

The intention of the questionnaire was to measure something other than the straightforward knowledge often tested by examinations. Written responses, however, may not be a good way of assessing psychiatric knowledge that would be used in medical or surgical settings - perhaps a practical test would be more valid (though not feasible in practice).

The absolute level of knowledge particularly at the beginning of the attachment seemed good (mean score $12.8 / 22$ ). The correlations of initial and final scores with examination grades, although statistically significant, were small only in absolute terms. A confounding factor could be that the questionnaires gave the students the impression that we were most interested in their learning "GP psychiatry". This is probably an accurate reflection of the aims of the teaching, and the examination at the end of the attachment. In particular, students may specifically try to learn the answers to our questionnaires with a view to doing well in the examination, even though they were not expecting a second administration of the questionnaire.

The second administration of the questionnaire was a full week before the students sat their end of attachment examination. As most students revise hard in the few days before the examination, this may give a better idea of the level of knowledge likely to be retained for future use than the examination itself.

In general, students' attitudes to psychiatry seem moderately favourable when they start the attachment and improve during the eight weeks. Two features of the questionnaire support this: firstly the increase in the acceptance of ECT as a valid treatment, and secondly the rate of interest in a psychiatric career, which rose from $4.1 \%$ to $9.8 \%$ over the seven weeks. (The actual proportion of hospital doctors in psychiatry is $11.8 \%$, and of consultants $13.2 \%$. Psychiatrists make up $6.5 \%$ of all doctors (i.e. including GPs) (Department of Health, 1989)). In a recent survey of career choice among preregistration house officers, Nottingham Medical School produced the greatest proportion of respondents indicating psychiatry as their first choice career $-8.2 \%$ as against an overall rate of $4.1 \%$ (Ellin et al, 1986).

It would be valuable to compare these results with studies at other medical schools, especially those using a less integrated approach, to elucidate further the effectiveness of teaching psychiatric issues outside the psychiatric clerkship itself.

\section{Note}

The questionnaire used is available on request from the authors.

\section{References}

DepartMent of Health (1989) Medical and dental staffing prospects in the NHS in England and Wales 1988. Health Trends, 21, 99-106.

Ellin, D. J., Parkhouse, H. P. \& Parkhouse, J. (1986) Career preferences of doctors qualifying in the United Kingdom in 1983. Health Trends, 18, 59-63.

MAYOU, R. \& SMTT, E. B. O. (1986) Hospital doctors management of psychological problems. British Journal of Psychiatry, 148, 194-197.

Wuluinson, D. G., ToOne, B. K. \& Greer, S. (1983) Medical students' attitudes to psychiatry at the end of the clinical curriculum. Psychological Medicine, 13, 655-658. 